\title{
Espacio turístico y turismo cultural a través de la ruta Don Vasco en Michoacán, México
}

\author{
Tourism space and cultural tourism through the Don Vasco \\ route in Michoacán, Mexico
}

\author{
Federico Gerardo Zúñiga-Bravo ${ }^{1}$ \\ Instituto Nacional de Antropología e Historia (DEAS-INAH), \\ México
}

\begin{abstract}
Resumen
El objetivo de este trabajo es presentar la conformación del espacio turístico en el estado de Michoacán, México, con base en el análisis de la ruta Don Vasco. Una ruta turístico-cultural cuyo diseño, planificación y gestión busca promover el turismo cultural a través de la puesta en valor del patrimonio cultural y natural existente en dos de las diez regiones geográficas que caracterizan a la entidad: región Lacustre y región Meseta Purhépecha. La investigación se compone de dos secciones: la primera esboza la base natural, histórica y sociocultural que soporta el crecimiento turístico en el área de estudio; la segunda, mediante la aplicación del Modelo de Articulación Espacial como principal recurso metodológico, identifica los elementos en torno a los que se construye el espacio turístico: los recursos y servicios turísticos, los canales espaciales de articulación de los turistas, así como los flujos que estos originan desde ámbitos nacionales y extranjero.
\end{abstract}

Palabras clave: Espacio turístico; turismo cultural; ruta Don Vasco; ruta turística; Michoacán.

\begin{abstract}
The objective of this work is to present the conformation of the tourism space in the state of Michoacán, Mexico, based on the analysis of the Don Vasco route. A touristic-cultural route whose design, planning and management seeks to promote cultural tourism through the enhancement of the existing cultural and natural heritage in two of the ten geographical regions that characterize the entity: Lacustre and Meseta Purhépecha regions. The present research is comprised of two sections:

1 Doctor en Antropología por la Universidad Nacional Autónoma de México (UNAM), México. Dirección de Etnología y Antropología Social del Instituto Nacional de Antropología e Historia (DEAS-INAH). Correos electrónicos: federico_zuniga@inah.gob.mx
\end{abstract}


the first outlines the natural, historical and sociocultural basis that supports tourism growth in the study area; the second, by way of applying the Space Articulation Model as the main methodological resource, identifies the elements around which tourism space is built: the touristic resources and services, the spatial channels of tourist articulation, as well as the exchange flows that these originate at the national and foreign levels.

Keywords: Tourism space; Cultural tourism; Don Vasco route; Tourist route; Michoacán.

\section{Introducción}

A nivel global, México es uno de los principales destinos turísticos al ubicarse entre los diez primeros lugares del ranking mundial ocupando el octavo sitio, de acuerdo a la Organización Mundial de Turismo (OMT), y el vigésimo segundo lugar en el ranking de competitividad de viajes y turismo del World Economic Forum (WEF). Estimaciones de la Secretaría de Turismo Federal (SECTUR) refieren que tan sólo en 2017 arribaron al país alrededor de 39 millones de turistas extranjeros, dejando una derrama en ingresos de 21,300 millones de dólares, mientras que unos 233 millones de turistas nacionales (turismo doméstico) recorrieron el país. En términos económicos, esto significa que el superávit de la balanza turística nacional ascendió a 8, 271 millones de dólares (15.4\% de crecimiento) el año pasado (2017) (El Economista, 2018). Lo que confirma que el turismo es una de las fuentes más importantes de recursos financieros para la economía mexicana, aunado al posicionamiento de la nación como referente turístico internacional.

En el ámbito nacional, aunque los destinos de turismo de sol y playa siguen predominando en la captación del mercado interno y extranjero $^{2}$, en los últimos años la diversificación y ampliación de la oferta ha permitido la inclusión de otros segmentos cuyo crecimiento ha permitido a México mantenerse entre los primeros lugares de competitividad, como se mencionó líneas arriba. Entre estos segmentos destaca el turismo de naturaleza ${ }^{3}$ (ecoturismo, turismo rural, turismo de aventura), turismo de

2 Ejemplo de ello es Isla Mujeres, Quintana Roo, el cual de 2012 a 2017 registró un alza continua en la llegada de turistas de $180 \%$, seguido por Nuevo Vallarta, Nayarit, con 66\%, Los Cabos y Baja California Sur, con $51 \%$ de incremento (SECTUR, 2018).

3 Respecto al turismo de naturaleza, el amplio inventario de recursos naturales que sustenta esta modalidad lo constituyen 182 áreas naturales protegidas (ANP), 850 especies de reptiles, 530 especies de mamíferos, 23, 500 especies de flora y 150, 000 especies de aves. Asimismo, 8.7 millones de turistas (equivalente a $25 \%$ de los 35 millones que arribaron a México en 2016) realizaron al menos una actividad relacionada con el turismo de naturaleza. Mientras que uno de cada cuatro turistas efectuó por lo menos una actividad relacionada con el ecoturismo y el turismo de naturaleza o de convivencia en espacios rurales (SECTUR, 2017). 
negocios, turismo religioso, turismo de salud y el turismo cultural. Lo que representa un factor positivo con el objetivo de mantener su posición en el mercado global, gracias a su alto potencial de recursos naturales y culturales para su aprovechamiento turístico (Propin y Sánchez, 2002) pues el turista, como un consumidor cada vez más exigente, demanda calidad y autenticidad con relación a los lugares, culturas y ambientes que se le ofrecen" (Machuca, 2008: 59).

El interés por profundizar en el análisis del turismo cultural y las rutas turístico-culturales como elementos que inciden en la producción del espacio (turístico) se debe, por un lado, porque para el mercado nacional representa una derrama económica de aproximadamente 184 mil millones de pesos (SECTUR, 2016), lo cual ha sido posible gracias a que México es uno de los países ${ }^{4}$ con mayor número de sitios histórico-naturales y elementos culturales inscritos en la Lista de Patrimonio Mundial de la Organización de las Naciones Unidas para la Educación, la Ciencia y la Cultura (UNESCO, por sus siglas en inglés). Los cuales suman 34 elementos registrados ${ }^{5}$, a los que habría que agregar las 8 manifestaciones de carácter inmaterial ${ }^{6}$ que han sido consideradas en la Listas Representativas de Patrimonio Cultural Inmaterial (LRPCI), además de 111 Pueblos Mágicos ${ }^{7}, 187$ zonas arqueológicas y 1200 museos y galerías de arte. Lo que contribuye a que esta oferta sea una de las más apreciadas por los visitantes internacionales (SECTUR, 2016). Por el otro, debido a que los itinerarios culturales y las rutas turístico-culturales se han convertido en uno de los recursos territoriales de mayor crecimiento en las últimas décadas. Estas últimas, las rutas, han cobrado especial interés como productos turísticos que coadyuvan a un modelo sostenible de desarrollo territorial, además de

4 Ocupando el sexto lugar detrás de Italia, España, China, Alemania y Francia, y el primero en América Latina y el Caribe.

5 De los cuales 5 son bienes naturales, 27 son culturales y 2 son mixtos (natural-cultural).

6 1. Las fiestas indígenas dedicadas a los muertos (2008); 2. Lugares de memoria y tradiciones vivas de los otomí-chichimecas de Tolimán: en torno al territorio sagrado de Peña de Bernal (2009); 3. La ceremonia ritual de los Voladores (2009); 4. La pirekua, canto de los purhépechas (2010); 5. Los Parachicos en la fiesta tradicional de enero de Chiapa de Corzo (2010); 6. La tradición gastronómica de Michoacán. Cocina tradicional mexicana, cultura comunitaria, ancestral y viva. El paradigma de Michoacán (2010); 7. El Mariachi. Música de cuerdas, canto y trompeta (2011); y 8. La charrería, tradición ecuestre de México (2016).

7 Pueblos Mágicos es una denominación turístico-cultural que otorga la Secretaría de Turismo Federal (SECTUR) a aquellas localidades del país que cubren con una serie de requisitos y características que las hace merecedoras de dicho distintivo con el objetivo de convertirse en destinos de turismo cultural con el propósito de contribuir al desarrollo local. 
ser formas bien conocidas y difundidas de turismo, y en décadas recientes de turismo activo y cultural (Arcila, et. al., 2015; Morére, 2012).

En el caso de este trabajo, el análisis de la ruta Don Vasco, una ruta turístico-cultural cuyo diseño, planificación y gestión busca incidir en el desarrollo sustentable de los pueblos y comunidades indígenas purhépechas de Michoacán, aunado a su promoción como un importante destino de turismo cultural a través de la puesta en valor del patrimonio cultural y natural existente en dos de las diez regiones que conforman la entidad: región Pátzcuaro-Zirahuén (Lacustre) y región Purhépecha (Meseta Purhépecha-Cañada de los Once Pueblos) ${ }^{8}$, tiene como finalidad mostrar el proceso de producción del espacio turístico como elemento que contribuye, además de revelar los efectos espaciales de la ocupación turística, en la organización territorial de ambas regiones con fines de posicionar a la ruta como un producto turístico-cultural novedoso y sustentable en el mercado interno e internacional.

\section{Área de estudio. Las regiones Lacustre y Meseta Purhépecha en Michoacán, México.}

En este apartado, conviene mencionar algunas características fisiográficas, estadísticas, históricas y socioculturales por las cuales el estado de Michoacán ha sido considerado destino turístico desde mediados del decenio de 1920 hasta la actualidad, cuya amplia variedad de recursos naturales y culturales ${ }^{9}$ han contribuido desde entonces a la conformación del espacio turístico, además de sostener la oferta de actividades, productos y servicios de la ruta Don Vasco.

8 El Instituto Nacional de Geografía y Estadística (INEGI) y el Instituto Nacional para el Federalismo y el Desarrollo Municipal (INAFED), identifican en Michoacán 10 regiones con diversas características geográficas y político administrativas. Mientras que otros autores, mencionan 6 regiones, cuyo criterio principal es la selección de los municipios con mayor número de población: 1. Centro (Morelia), 2. Lacustre (Pátzcuaro), 3. Meseta Purhépecha (Uruapan), 4. Oriente (Zitácuaro), 5. Occidente (Zamora), y 6. Costa (Lázaro Cárdenas). Para fines de este trabajo, y con el objetivo de evitar confusiones, en adelante sólo se hará mención de ambas regiones donde se llevó a cabo la investigación como Región Lacustre y Región Meseta Purhépecha.

9 Sobre los recursos naturales con los que cuenta Michoacán, conviene destacar que el 35.7\% de la superficie del estado (2,097100.2 hectáreas) está cubierta de vegetación natural: bosque (16.1), pastizal (9.9\%), selva $(9.7 \%)$ y matorral xerófilo $(0.04 \%)$. Mientras que el $64.3 \%$ corresponde a terrenos para la agricultura, zonas urbanas, áreas sin vegetación, cuerpos de agua y vegetación secundaria. Respecto a los recursos culturales se hablará con mayor detalle en el cuerpo del texto. 
De acuerdo con el Instituto Nacional para el Federalismo y el Desarrollo Municipal (INAFED) y el Instituto Nacional de Geografía y Estadística (INEGI), el estado de Michoacán de Ocampo, nombre oficial de la entidad, se sitúa en la porción centro-oeste de la República Mexicana, longitud oeste. Limita al norte con los estados de Jalisco y Guanajuato, al noroeste con el estado de Querétaro, al este con los estados de México y Guerrero, al oeste con el océano Pacífico y los estados de Colima y Jalisco, al sur con el mismo océano, señalado líneas anteriores, y el estado de Guerrero. Por su extensión territorial ocupa el décimo sexto lugar nacional, con una superficie mayor a los 58,000 $\mathrm{km}_{2}$, que representa el $3 \%$ de la extensión del territorio nacional. La entidad cuenta con $228 \mathrm{~km}$. de litoral ( $2 \%$ del total nacional) y $1,490 \mathrm{~km}_{2}$ de aguas marítimas.

En cuanto a su orografía, a Michoacán se localiza entre dos grandes provincias fisiográficas, que son: la Sierra Madre del Sur y el Sistema Volcánico Transversal y Valles Intermontañosos (Cordillera Neovolcánica o Tarasco-Náhuatl). La Sierra Madre del Sur atraviesa al estado en aproximadamente $200 \mathrm{~km}$ en la zona suroeste (entre los municipios de Chinicuila y Arteaga). Se le considera como la continuación de la Sierra Madre Occidental y de otras Sierras de América del Norte -Sierra Nevada, Montañas Rocallosas- (INAFED, s.f.).

La otra región montañosa del Estado, la constituye el Sistema Volcánico Transversal (o Cordillera Neovolcánica) se localiza al sur de la altiplanicie mexicana y se formó como consecuencia de la aparición de numerosos volcanes. En este Sistema, hay una región orográfica que queda representada por la Sierra de Tancítaro, que se conecta en el Noroeste con la de Peribán y se enlaza con las Sierras de San Ángel y Tarécuato, y por el Este con las de Paracho y Carapan (en esta zona se ubica la Meseta Tarasca donde se localiza el volcán Paricutín $\left.{ }^{10}\right)$.

Respecto a sus características hidrográficas ${ }^{11}$, se presenta una red fluvial que tiene como arterias principales a dos grandes ríos del país: el

10 El Paricutín, cuyo surgimiento en 1945 lo sitúa como uno de los volcanes más jóvenes de México, ha sido desde 1980 un lugar de interés para el desarrollo del geoturismo y el turismo de aventura, promovido principalmente por los pobladores de la comunidad indígena de Angahuan. Véase Sánchez Crispín y Propin (2014).

11 Tres grandes sistemas hidrográficos denominados que, por su posición geográfica: Norte, Centro y Sur, además del sistema fluvial costanero, son los que se encuentran en la entidad (Sistema del Norte, Sistema del Centro y Sistema del Sur). Lo que se traduce en 85,354.3 hectáreas ocupadas por cuerpos de agua: 30 ríos, 15 presas y 6 lagos. 
Lerma y el Balsas; por otra parte, los ríos de la región de Arteaga y Coalcomán (Sistema del Sur) no tienen ninguno principal, pues desembocan directamente en el Océano Pacífico y por último la pequeña red interna representada por los lagos de Cuitzeo (Sistema Norte), Pátzcuaro y Zirahuén (Sistema Centro). En el caso de los lagos de Pátzcuaro y Zirahuén, el primero ocupa una superficie de $1,525 \mathrm{~km}_{2}$ aproximadamente, comprendiendo los municipios de Erongarícuaro, Pátzcuaro, Quiroga y Tzintzuntzan. La cuenca que da origen al lago se alimenta de numerosas corrientes tanto superficiales como subterráneas. Entre las primeras se destacan las de los ríos San Gregorio y Chapultepec, así como los arroyos de Santa Fe y Soto. En el interior del lago se levantan los islotes denominados Janitzio, Yunuén, La Pacanda, Tecuén, Jarácuaro, Urandén y Carián.

Con relación al lago de Zirahuén, una cuenca de $615 \mathrm{~km}_{2}$, recibe los aportes de los arroyos Manzanilla y Zinamba, los cuales nacen en la población de Santa Clara del Cobre.

La mención especial que merecen estos lagos, Pátzcuaro y Zirahuén, localizados en la zona centro-norte del estado, en una de las partes más altas del Eje Volcánico Transversal, se debe a que, por ejemplo, para el INAFED constituyen los centros de mayor atracción turística de la entidad. Sobretodo el de Pátzcuaro, del que se hablará con mayor detalle más adelante, siendo la actividad pesquera, junto a las actividades agropecuarias, producción artesanal y el turismo, una de las más importantes para las poblaciones aledañas al lago y un elemento fundamental para la cultura purhépecha (Ávila, 2008). Aunque con graves problemas de contaminación y reducción del volumen hídrico, lo que ha derivado en graves problemas socio-ambientales en las últimas décadas para dicha zona, como en la imagen turística del lugar.

Michoacán está conformado por 113 municipios, los cuales están distribuidos en diez regiones ${ }^{12}$ cuya población total, de acuerdo a la Encuesta Intercensal efectuada por INEGI en 2015, es de 4,584.471 habitantes, de los cuales 140,820 son hablantes de lengua indígena (HLI). Si bien hay presencia de 44 lenguas indígenas en la entidad, derivado principalmente de movimientos migratorios, las cinco principales son: purhépecha $(83.2 \%)$, náhuatl $(6.5 \%)$, mazahua $(3.9 \%)$, mixteco $(0.8 \%)$ y otomí

12 1. Lerma-Chapala, 2. Bajío, 3. Cuitzeo, 4. Oriente, 5. Tepalcatepec, 6. Purhépecha, 7. Pátzcuaro-Zirahuén, 8. Tierra Caliente, 9. Sierra-Costa, 10. Infiernillo. 
(0.4\%), concentrada en quince municipios (INEGI, 2013). La población purhépecha es la de mayor densidad demográfica en el estado, cuya principal ubicación se encuentra en dos de las diez regiones antes mencionadas: región purhépecha (Meseta Purhépecha, conformada por 43 localidades que pertenecen a 11 municipios) y región Pátzcuaro-Zirahuén (compuesta por 35 localidades que pertenecen a 7 municipios), conocida comúnmente como región o zona Lacustre ${ }^{13}$.

Resaltar la composición étnica en estas dos regiones se debe a que, además de concentrar a la mayoría de población purhépecha (entre el $80 \%$ y $88 \%$ ), la Meseta es considerada como una de las regiones más pobres de Michoacán debido a que sus condiciones materiales de existencia (ingreso, empleo, vivienda, educación y salud) están por debajo del promedio estatal y nacional (Ávila, 2008). Por otro lado, aunque ambas regiones presentan entornos naturales distintos, el predominio cultural de los purhépechas representa un patrón homogéneo por el cual algunos pueblos y comunidades se han convertido en sitios de interés turístico, como se describirá más adelante.

Es por ello que para el gobierno estatal el trazo de la ruta Don Vasco por el territorio que conforma a estas regiones, además de contribuir en la producción del espacio turístico, tiene como objetivo posicionarla como un producto competitivo en materia de turismo cultural que, a su vez, represente la posibilidad de generar desarrollo endógeno en términos de sustentabilidad cultural, natural y económica para los pueblos y comunidades incluidos en la ruta.

\section{El turismo en Michoacán. Antecedentes históricos y contexto actual.}

Aunque la actividad turística en el estado de Michoacán tiene su origen a finales del siglo XIX, gracias a que el ferrocarril facilitó la conexión entre regiones, entre 1920 y 1930 tuvo mayor auge debido a que el estado comenzó a promocionarse en el ámbito internacional antes de que se concluyera la carretera entre las ciudades de México y Guadalajara, aunado a la difusión del lago de Pátzcuaro como uno de los principales atractivos

13 Aunque algunos autores, véase Kemper (1987), señalan que la región purhépecha se conforma por cuatro zonas geográficas (subregiones): 1. La sierra, 2. El área del lago de Pátzcuaro, 3. La cañada (conocida regionalmente como "Cañada de los Once Pueblos", y 4. El área norte y noroeste del lago de Pátzcuaro. 
turísticos para visitar las islas de Janitzio y Jarácuaro (Martínez Ayala, 2016), situadas en la región Lacustre:

Pátzcuaro y la región del lago ofrece una amplia gama de atracciones geográficas, históricas y culturales a más de 125,000 turistas anuales. El sabor indígena de la región -ejemplificado en el famoso tianguis del viernes y las redes en forma de mariposa de los pescadores de Janitzio- es básico para la promoción de la industria turística (Kemper, 1987:76).

Como resultado de dicha propaganda, esto propició la conformación de un imaginario social y turístico a partir del cual el turismo estadounidense y nacional buscaba encontrar imágenes estereotípicas de lo "mexicano" a través de las representaciones visuales sobre los espacios rurales y la cultura local mediante el consumo anticipado de imágenes en publicaciones especializadas como Mexican Folkways, y tarjetas postales que eran obsequiadas por amigos y conocidos que recomendaban visitar esos “auténticos destinos mexicanos" (Martínez Ayala, 2016), como el estado de Michoacán. A ello habría que agregar que los procesos de industrialización y urbanización en el país a partir de 1940 incidieron por igual en esta entidad con el propósito de estimular el desarrollo estatal y regional, lo cual sucedió de forma particular en la Meseta Purhépecha gracias a su cercanía con centros urbanos como Uruapan, Zacápu, Los Reyes, Zamora, Jacona y Pátzcuaro:

Un tercer aspecto en el desarrollo urbano tarasco ${ }^{14}$ es el turismo. En su carácter de actividad del "sector servicios", el turismo tiene la ventaja de ocupar más mano de obra intensiva que las actividades agrícolas o industriales. Pátzcuaro y la región del lago han sido un lugar de atracción turística desde los años 1940 (Stanislawski, 1950:50), y el Parque Nacional Eduardo Ruíz en Uruapan, así como el lago de Camécuaro, cerca de Tangancícuaro, reciben así mismo muchos visitantes. Incluso el lugar del volcán Paricutín y el pueblo enterrado de San Juan Parangaricutiro, situado a 25 kilómetros al oeste de Uruapan, se ha convertido en una atracción turística. Además, muchas ciudades y pueblos tienen fiestas famosas que atraen a turistas de

14 Los términos "tarasco" y "purhépecha" hacen referencia a entidades históricas y sociales diferentes. Mientras lo tarasco fue una entidad antigua dominante, lo purhépecha fue una dominada y, por tanto, su nombre expresa su pasado bajo control colonial del imperio español. No obstante, hoy en día los purhépechas se auto adscriben al grupo étnico bajo ambos términos. Véase García Mora (2011). Para el caso de este trabajo, y con el fin de evitar confusiones, se usará sólo el vocablo purhépecha. 
Guadalajara, la ciudad de México y otros centros metropolitanos (Kemper, 1987: 76).

En la actualidad, muchos de estos destinos y recursos descritos por Kemper a mitad del siglo pasado son los que siguen perfilando al estado como destino turístico cultural a nivel nacional. Ejemplo de ello es que tan sólo en 2016, la secretaría de turismo estatal refiere que los indicadores de afluencia turística y derrama económica registraron un crecimiento del $8.1 \%$. (8 millones 205 mil visitantes y turistas) y $4.4 \%$, equivalente a 10 mil 164 millones de pesos respectivamente en comparación con el año anterior (2015). Mientras que los períodos de mayor afluencia del año fueron verano y Noche de Muertos "Noche de Ánimas", teniendo como principales destinos de la entidad a Morelia (que recibió 2.7 millones de personas, destacando los flujos de turismo nacional); Pátzcuaro (con 1.8 millones de visitantes); Costa (1 millón de personas); Zona de la Monarca (638 mil); Zamora (574 mil visitantes) y entre Uruapan y Apatzingán 1.8 millones de viajeros. Cuyos principales rubros de gasto fueron transporte, hospedaje, compras, artesanías y otras actividades sin especificar (El Sol de Morelia, 2017).

La importancia del turismo en Michoacán desde principios del siglo XX hasta el día de hoy tiene una estrecha relación con la organización territorial para la producción del espacio turístico y la puesta en valor de la cultura y la naturaleza como sus principales recursos, ya que el turismo, además de actuar como un vehículo que transforma no sólo los medios físico, socioeconómico y demográfico de los territorios donde se inserta, al fomentar la articulación de nuevas regiones socioeconómicas (Lozato, 1990; Callizo, 1991; López, 2002), incide también en la conversión de la cultura y la naturaleza como recursos que sostienen la oferta de productos y atractivos. Asignando nuevas valoraciones a estos, aunado a que se vuelven el principal referente turístico-visual de la entidad:

En Michoacán, la actividad turística es el principal motor de desarrollo social, cultural y económico. El turismo es la principal fuente de empleo y bienestar para sus habitantes. Michoacán es un destino sustentable, competitivo e innovador que sirve como ejemplo de desarrollo para México y el mundo [...] Michoacán tiene una gran vocación turística, una gran riqueza cultural, con una vasta oferta de ferias y festivales, encuentros de 
cocina, nuestros ocho pueblos mágicos y nuestros patrimonios culturales tangibles e intangibles; ecoturismo, turismo de aventura y turismo comunitario en las diferentes regiones del estado. (Programa Sectorial de Turismo del Estado de Michoacán 2015-2021: 12; 29)

Lo enunciado en la cita anterior se sustenta a partir de que Michoacán cuenta con varias manifestaciones culturales (materiales e inmateriales) y naturales declaradas Patrimonio Cultural de la Humanidad por la UNESCO, entre las cuales destaca el Centro Histórico de la Ciudad de Morelia (1991), las fiestas indígenas dedicadas a los muertos (2008), la Reserva de la Biósfera de la mariposa monarca (2008), la pirekua, canto de los purhépechas (2010), la tradición gastronómica de Michoacán. Cocina tradicional mexicana, cultura comunitaria, ancestral y viva: El paradigma de Michoacán (2010). A las que hay que añadir la categorización de 8 localidades en calidad de Pueblos Mágicos ${ }^{15}$, tres zonas arqueológicas localizadas entre la zona lacustre ( comunidad indígena de Ihuatzio y cabecera municipal de Tzintzuntzan) y la Meseta Purhépecha (cabecera municipal de Tingambato), el Tianguis Artesanal de Domingo de Ramos que se efectúa en la ciudad de Uruapan en el contexto de la celebración católica de Semana Santa, considerado como el tianguis artesanal más grande e importante de Latinoamérica, el programa Club de Calidad Tesoros de Michoacán, promovido por la Secretaría de Turismo Federal, y la ruta Don Vasco.

Lo descrito líneas arriba, es una muestra del papel que el turismo ejerce en los procesos de producción del espacio turístico y la reorganización socio-territorial de las diez regiones que conforman al estado de Michoacán. Ejemplo de ello la regionalización turística del territorio estatal, si se considera que una de las formas para comprender la regionalización se debe a la identificación de ciertas particularidades económicas que presenta el territorio o un espacio en particular, lo que contribuye a explicar la regionalización turística de Michoacán ${ }^{16}$ como parte, por un lado, de su encadenamiento en la regionalización turística del país (Propin y Sánchez, 2002) y, por otra, debido a que este tipo de división regional

15 Estas son: 1. Angangueo, 2. Cuitzeo, 3. Jiquilpan, 4. Pátzcuaro, 5. Santa Clara del Cobre, 6. Tacámbaro, 7. Tlalpujahua, 8. Tzintzuntzan.

16 Que, de acuerdo a los recursos naturales y culturales existentes en cada una de éstas y sus características geográficas están delimitadas de la siguiente manera: 1. País de la Monarca, 2. Región Morelia, 3. Región Zamora, 4. Región Pátzcuaro, 5. Región Uruapan, 6. Región Apatzingán, y 7. Región Costa. 
del territorio resulta conveniente para los promotores turísticos, pues el hecho de que se delimiten regiones culturalmente representativas con tal propósito contribuye en acondicionar y habilitar cierta organización territorial con el objetivo de poner en valor los distintos elementos vinculados con el territorio y las poblaciones que lo habitan, de manera que la inversión destinada a los proyectos turísticos cuente con una oferta diversificada que garantice su éxito (Machuca, 2008).

Aunado a esta regionalización turística, conviene señalar que todos estos eventos, lugares, sitios arqueológicos, producción artesanal, ciudades patrimonio de la humanidad, recursos naturales, elementos y prácticas culturales son los que sostienen la oferta turística de la entidad. Incluso, en la opinión de algunos funcionarios entrevistados de la secretaría de turismo estatal, durante el trabajo de campo, señalan que "Michoacán se distingue por ser un importante destino de turismo cultural" gracias al amplio acervo de bienes culturales existentes, principalmente en ciudades como Morelia, Pátzcuaro y Uruapan, así como en los pueblos y comunidades purhépecha de ambas regiones de estudio. Estas últimas, al ser consideradas como potenciales nichos de mercado para el turismo cultural: su entorno geográfico, sus sitios arqueológicos, su arquitectura vernácula y religiosa, su artesanía, sus fiestas, su gastronomía, sus danzas y su música (Flores, et. al., 2016: 31), constituyen los principales recursos turísticos a través de su puesta en valor en la ruta Don Vasco. Lo que plantea un nuevo campo de relaciones entre instituciones, empresas, patrimonio cultural y pueblos indígenas (Flores, et. al., 2016).

\section{El espacio turístico y las rutas turístico-culturales. El caso de la ruta Don Vasco.}

La localización de la ruta turístico-cultural "Don Vasco", de acuerdo a sus rasgos geográfico-físicos, se ubica entre las regiones Lacustre y Meseta Purhépecha. Asimismo, este trabajo toma en cuenta la regionalización turística que ha delimitado la entidad, donde la ruta se emplaza en en cuatro regiones: Morelia, Pátzcuaro, Uruapan y Zamora, las cuales han contribuido de forma significativa al desarrollo industrial, urbano, económico y turístico de Michoacán. Por otra parte, los principales nodos que conforman esta ruta son las ciudades de Morelia, Pátzcuaro y Uruapan, además se incluyen otros municipios (Cuitzeo, Quiroga, Erongarícuaro, 
Tzintzuntzan, Salvador Escalante, Tingambato, Los Reyes, Paracho, Zamora), así como otras poblaciones urbanas y rurales que, sin duda, contribuyen a sustentar el turismo de la ruta (Figura 1.).

Si se considera que el espacio geográfico es modificado por la acción humana a partir del desarrollo de ciertas actividades que inciden en la organización y uso del territorio y de sus habitantes (Coll-Hurtado, 2006) como sucede, en este caso, con el turismo, se puede afirmar que el espacio turístico es aquella porción del espacio geográfico en el cual se ejercen prácticas socio-espaciales relacionadas con actividades de ocio, recreación y turismo (Hiernaux, 2011).

Figura 1. Localización de la ruta Don Vasco, Michoacán, México.

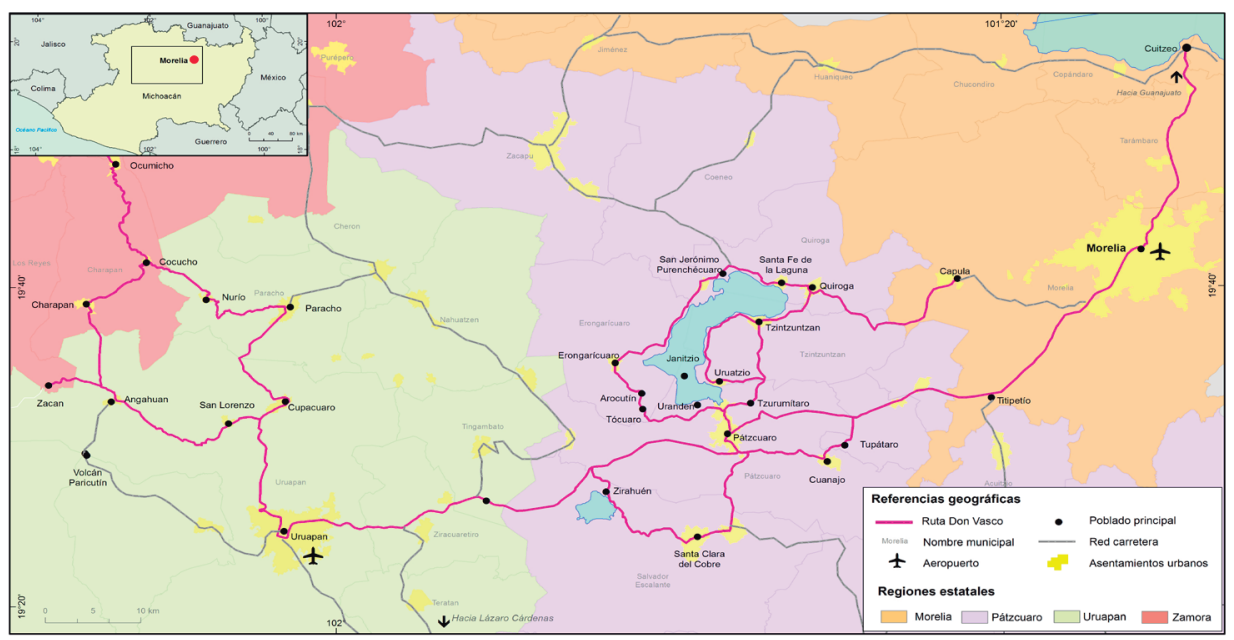

Fuente: trabajo de campo, marzo-abril, 2018.

Para ampliar la definición anterior sobre el espacio turístico se puede decir que comprende aquellas partes del territorio donde es posible atestiguar la práctica de actividades turísticas. Para ello, el elemento clave con el cual es posible delimitar el espacio turístico son los atractivos, representados en diversas categorías, tamaño y discontinuidad espacial (Boullón, 2006).

A partir de un replanteamiento crítico de las relaciones entre el turismo y el espacio, es que se busca analizar cómo el espacio participa en el turismo y, al mismo tiempo, cómo el turismo contribuye a la producción 
y transformación del espacio (Almirón, 2004). Por tanto, el consumo del espacio por el turismo: la producción del espacio turístico o la transformación del espacio por el turismo (Chadefaud, 1987), conlleva señalar que éste no sólo se concibe por sus atributos físicos, sino también por sus cualidades simbólicas y por las formas que adopta el territorio en función del turismo, debido a que cualquier tipo de turismo que se lleve a cabo tiene una fuerte connotación espacial, pues su ejercicio supone el consumo de elementos emplazados en la superficie terrestre; su dinamismo se basa en regiones emisoras y receptoras, flujos de personas, mercancías, capitales, cuyos alcances pueden ser nacionales e internacionales (Bringas y González, 2003). Por tanto, "un territorio turístico es un espacio en (dimensión físico-locativa) el que se llevan a cabo actividades turísticas las cuales en mayor o menor grado modifican el paisaje; es por así decirlo, el polígono industrial del ocio" (Nogués Pedregal, 2017: 125).

En ese sentido, las rutas pueden considerarse también como elementos que intervienen en la producción del espacio turístico y la organización territorial, a partir de la visibilización de los recursos culturales y naturales que se promocionan en calidad de atractivos dentro de las rutas mediante su puesta en valor, pero también como factor que influye en dinamizar las economías locales por donde estas se trazan.

Las rutas han venido a integrarse a la oferta del turismo cultural, cuya demanda va en aumento por encima del turismo de masas y otros segmentos. Esto se debe a que "la ruta consiste, por su propia esencia, en recorrer y al mismo tiempo ver, conocer, sentir (cada vez más lo último que lo primero), no permanecer, como puede ocurrir con gran parte del turismo de sol y playa, urbano, el de espectáculos o el deportivo" (Torres Bernier, 2006:84).

Las rutas turísticas tienen por función la promoción de un área, una región o de una temática con potencialidad turística, a partir de abordar temáticas culturales o de índole natural (Chan, 2005), aunado a la consideración de los canales espaciales de circulación de los turistas y los flujos que estos originan tomando en cuenta los lugares de origen, nacionales e internacionales. Lo que conlleva enfatizar que las rutas turísticas se relacionan esencialmente con la infraestructura vial que articula a un conjunto de recursos (Morére, 2012; Chan, 2005).

A su vez, pueden constituir en sí mismo un recurso, un producto o bien, un destino en el que pueden insertarse muchos productos, 
dependiendo su origen y posición en la cadena de producción turística, lo que permite visualizarlas, desde el enfoque turístico, bajo una perspectiva tripartita: como recurso, destino y producto:

En el primer caso, se trata de rutas que, aunque existiendo en la cultura no se han trasladado al mundo del turismo, pero que potencialmente pueden hacerlo en un momento determinado, por decisión del mercado, por una política pública en esa dirección. En el segundo, el turista acude a visitar la zona "por la libre" siguiendo referencias históricas o el material de difusión consultado. Cuando pasa a ser un producto, el tercer caso, es porque son ofertadas por los operadores y se materializan en "paquetes" en forma de circuitos y de excursiones, pudiendo en ambos casos tener diversos niveles de complejidad (Torres Bernier, 2006:86).

Con base en lo anterior, se puede sostener que la ruta Don Vasco cumple con estas tres características. En primer lugar, aunque no posee propiamente los rasgos de un itinerario cultural, cuyo trazo debe tener un sustento histórico como bien refiere Torres Bernier (2006), su planeación y diseño por parte la secretaría de turismo del estado de Michoacán, en colaboración con otras instancias gubernamentales federales e incluso internacionales ${ }^{17}$, obedece a un conjunto de políticas públicas (turísticas, económicas, de ordenamiento y desarrollo urbano-territorial) y estrategias de marketing (segundo caso) en ferias nacionales e internacionales de turismo, páginas web, televisión y medios impresos que buscan promocionar los acervos culturales (patrimonio cultural material e inmaterial) y recursos naturales, estrechamente vinculados a los pueblos y comunidades purhépecha de las dos regiones por las que atraviesa la ruta, como los principales recursos turísticos. Es por ello que "las rutas se han convertido en el producto más utilizado para vertebrar la oferta patrimonial de muchos destinos turísticos" (Arcila, et. al., 2015: 465), aunado al posicionamiento en el mercado de la imagen de Michoacán como destino turístico-cultural, cuya construcción data desde principios del siglo XX, como se refirió líneas arriba, y mediante lo que se ha constituido como la marca "Don Vas$\mathrm{co}^{18 \%}$. Asimismo, como tercer caso, cabe agregar la creación del Centro de

17 Como la Agencia Española de Cooperación Internacional para el Desarrollo (AECID).

18 Vasco de Quiroga, mejor conocido como “Tata Vasco” entre los indígenas purhépecha de la Nueva España, fue un humanista y el primer obispo de Michoacán a quien se le atribuye fundar los primeros hospitales de indios en lo que hoy es la Ciudad de México y en las poblaciones de Santa Fe de la Laguna y Uruapan, en Michoacán, además de haber asignado oficios a cada poblado para su especialización en la producción 
Interpretación Multimedia Ruta Don Vasco (Figura 2.), localizado en la ciudad de Pátzcuaro, cuyo objetivo primordial es que, por medio de la interacción con herramientas digitales y contenidos museográficos, el turista cuente con la suficiente información temática sobre la ruta para diseñar y trazar su propio itinerario dentro de ésta.

De esta forma, el centro multimedia, además de contribuir en la construcción de ese imaginario turístico sobre Michoacán y la ruta Don Vasco, canaliza las expectativas y deseabilidades del turista mediante la previa elección de los lugares y atractivos insertos en la ruta y que más le interese conocer, tras haber realizado el recorrido de este espacio museístico.

Figura 2. Publicidad del Centro de Interpretación Ruta Don Vasco, Michoacán, México.
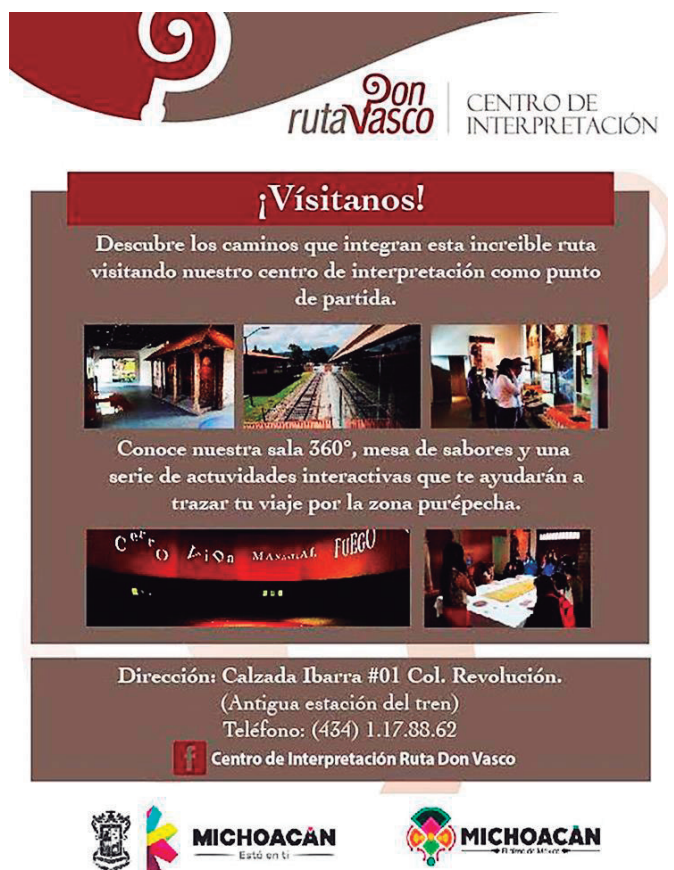

MICHOACAN

Fuente: Trabajo de campo, marzo-abril, 2018.

artesanal. Lo cual es una de las principales características que hoy en día distingue a Michoacán. Asimismo, hoy en día son innumerables las calles, escuelas, asociaciones, gremios, sociedades y lugares que llevan su nombre en Michoacán. Es el caso en particular del municipio y cabecera municipal de Quiroga, anteriormente llamada Cocupao. 


\section{El Modelo de Articulación Espacial para el análisis del espacio turístico en la ruta Don Vasco}

La revisión de datos cuantitativos y cualitativos, los recorridos en campo en las ciudades de Morelia, Pátzcuaro y Uruapan, así como en las localidades de Tacámbaro, Ihuatzio, Tzintzuntzan, Tingambato y Santa Clara del Cobre constituyeron una primera aproximación al universo de estudio para la recolección de información mediante el uso del registro etnográfico, la realización de entrevistas a profundidad con actores clave y la aplicación de encuestas ${ }^{19}$, como principales técnicas de investigación, con el fin de identificar los principales elementos patrimoniales, ciudades y poblaciones que se ofertan, caracterizar los itinerarios de los turistas, a la par de identificar los lugares de emisión de los flujos turísticos y los medios de articulación con el propósito de elaborar cartografías temáticas con las cuales fue posible analizar y explicar la producción del espacio turístico a través de la ruta Don Vasco. Para ello, conviene resaltar el uso del Modelo de Articulación Espacial propuesto por Hiernaux (1989) como principal estrategia metodológica, cuyo objetivo fue analizar la conformación del espacio turístico a través de la ruta Don Vasco. El cual se explica a continuación y en la Figura 3, a partir de su adecuación al objeto de estudio de esta investigación:

1. La existencia y estructura de un núcleo. Constituido, en este caso, por los municipios y localidades: Morelia, Pátzcuaro, Erongarícuaro, Quiroga, Ihuatzio, Santa Fe de la Laguna, Tupátaro, Tiripetío, Los Reyes, Paracho, Pátzcuaro, Salvador Escalante, Tzintzuntzan y Uruapan ${ }^{20}$, de las dos regiones seleccionadas (Región Lacustre y Región Meseta Purhépecha) en las que la ruta Don Vasco tiene su principal trazo e impulso;

2. Los flujos generados por tal presencia. Representados por los turistas nacionales e internacionales que arriban a ambas regiones, motivados por la oferta de recursos turísticos contenidos en los municipios y localidades insertas en la ruta.

19 Esta primera temporada de trabajo de campo tuvo una duración 24 días (15 de marzo al 7 de abril de 2018), aprovechando el periodo vacacional de Semana Santa por ser una de las temporadas de mayor afluencia de turistas a Michoacán, en la cual se efectuaron 20 entrevistas a profundidad con actores clave, además de la aplicación de 50 encuestas con el propósito de conocer los lugares de origen de los visitantes y así identificar los principales lugares emisores de turistas.

20 Aunque no se mencionan todas las poblaciones, el total incluido en la ruta se conforma por 12 cabeceras municipales y 105 comunidades a través de 14 municipios del estado. Incluyendo 4 Pueblos Mágicos (Cuitzeo, Pátzcuaro, Tzintzuntzan y Santa Clara del Cobre) y una ciudad Patrimonio de la Humanidad (Morelia). 
Federico Gerardo Zúñiga-Bravo

Espacio turístico y turismo cultural a través de la ruta Don Vasco en Michoacán, México

3. Los actores interesados en promover y consumir la oferta local de productos y servicios turísticos. Representado por los actores locales-regionales, nacionales y trasnacionales que participan y promueven el turismo, como instituciones nacionales, estatales, municipales e internacionales: Secretaría de Turismo Federal (SECTUR), gobierno del estado de Michoacán, Fomento Nacional de Turismo (FONATUR), Comisión Nacional para el Desarrollo de los Pueblos Indígenas (CDI), Secretaría de Comunicaciones y Transportes (SCT), Agencia Española de Cooperación Internacional para el Desarrollo (AECID), entre otras. Asimismo, empresarios nacionales, estatales y locales, turistas nacionales y extranjeros, así como los miembros de las comunidades que apuestan por el turismo como actividad económica complementaria, entre otros actores.

Figura 3. Nodos, infraestructura y recursos turísticos (culturales y naturales) que conforman el espacio turístico de la ruta Don Vasco, Michoacán, México.

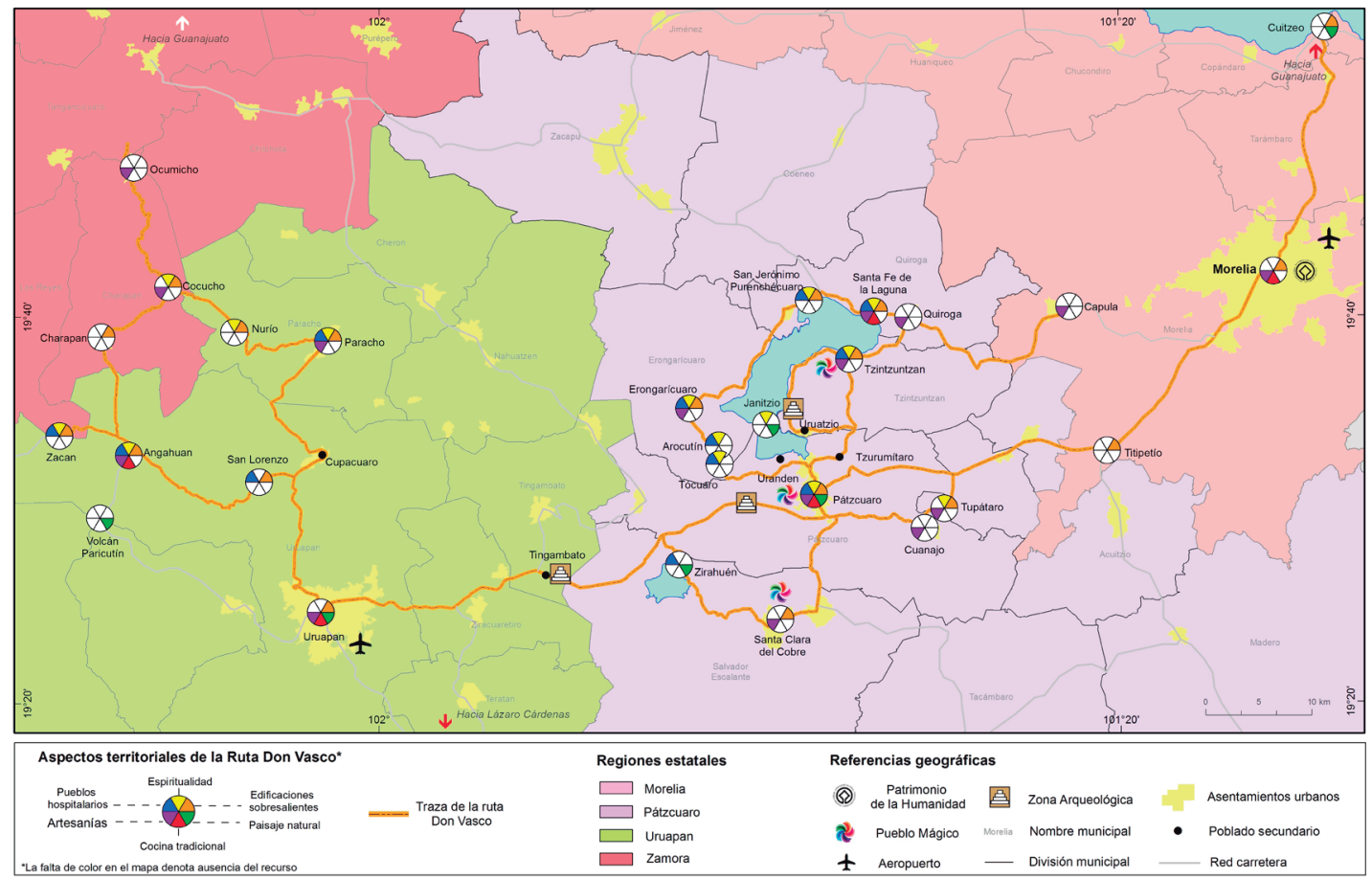

Fuente: trabajo de campo, marzo-abril, 2018. 
Con base en el análisis efectuado, y la argumentación teórico-metodológica, enunciada líneas arriba, la Figura 3 revela cómo se constituye la ruta Don Vasco a partir de diferentes elementos territoriales que contribuyen a la conformación del espacio turístico en esta porción de Michoacán. En primer lugar, se observan recursos turísticos de índole cultural y natural en las regiones estatales de Morelia, Pátzcuaro, Uruapan y Zamora.

La mayor oferta de los sitios con actividad turística se ubica alrededor del Lago de Pátzcuaro, este se refleja en los tres pueblos mágicos (Pátzcuaro, Tzintzuntzan y Santa Clara del Cobre) que se promocionan y en la cantidad de poblados próximos a éste. Cada lugar tiene diferentes características que lo hacen singular, unos poseen edificaciones sobresalientes prehispánicas y coloniales -como Pátzcuaro, Tzintzuntzan, Ihuatzio y Santa Clara del Cobre-, algunos tienen paisajes naturales -la ribera del lago de Pátzcuaro- y, en otros, su cocina tradicional es única. Por otro lado, cabe señalar que la vecindad geográfica del lago con la ciudad de Morelia es fundamental para el desarrollo del turismo, debido a que la infraestructura carretera y otros servicios, posibilitan el traslado de los visitantes, en contraparte de los poblados que se localizan en la región de la Meseta.

De esta manera, la creación y localización de la ruta Don Vasco en estas regiones puede considerarse como uno de los elementos que contribuyen a la continuidad en la conformación del espacio turístico y la estructura territorial del turismo en Michoacán, si se toma en cuenta que a través de ella lo que busca el gobierno estatal, principal promotor de esta, es integrar los pueblos y comunidades purhépecha que por contar con una serie de elementos patrimoniales (culturales y naturales) en calidad de recursos turísticos, su puesta en valor enriquezca la oferta de turismo cultural que poseen ciudades como Morelia, Pátzcuaro y Uruapan, junto a los Pueblos Mágicos como el mismo Pátzcuaro, Cuitzeo, Tzintzuntzan y Santa Clara del Cobre.

Como se señaló en párrafos anteriores, el proceso de turistificación en Michoacán se remonta a mediados del siglo XX, cuyo mayor auge se produjo en la región Lacustre de Pátzcuaro, aunque también en otros municipios urbanos como Morelia y Uruapan. Actualmente, se considera que las ciudades de Morelia, Pátzcuaro y Uruapan son los grandes ejes económicos y de servicios de la región (Plan Estratégico Ruta Don Vasco 20102025), ya que junto con la región Oriente donde se encuentra la Reserva 
de la Biósfera de la Mariposa Monarca, la ciudad de Zamora y la costa, los cuales son los principales destinos de la entidad porque concentran el mayor porcentaje en cuanto al número de establecimientos de hospedaje $\mathrm{e}$ infraestructura de servicios orientados al turismo. Ejemplo de ello es que Michoacán cuenta con 800 hoteles y cerca de 25,000 cuartos de hospedaje, así como 495 restaurantes, bares, cafeterías y centros nocturnos. Gracias a ello, la entidad se ubica en el octavo lugar a nivel nacional en cuanto a establecimientos de hospedaje y servicios turísticos (INEGI, 2013). Por tanto, no es fortuito que estas ciudades se presenten como el eje articulador de la ruta, si se considera la distancia que hay entre éstas. La distancia entre Morelia y Pátzcuaro son $58 \mathrm{~km}$, con un tiempo promedio de traslado de 55 minutos, y entre Pátzcuaro y Uruapan hay $57 \mathrm{~km}$, con un tiempo aproximado de recorrido de 1 hora con 10 minutos.

Cabe agregar que, las rutas turísticas se relacionan directamente con la infraestructura vial que articula a un conjunto de recursos, es importante recalcar que la infraestructura carretera facilita la movilidad del turista en menor tiempo desde los principales lugares emisores. Entre las principales vías de comunicación, actualmente opera la autopista Cuitzeo-MoreliaPátzcuaro-Uruapan-Lázaro Cárdenas con cuatro carriles. Además, también cuenta con la autopista México-Morelia-Guadalajara (vía corta), que sitúa a la entidad en el séptimo lugar a nivel nacional en infraestructura de carreteras troncales y de cuota (INEGI, 2013).

Asimismo, la infraestructura aeroportuaria está integrada por los aeropuertos internacionales de Morelia, "Francisco J. Múgica”, y Uruapan, “Gral. Ignacio López Rayón”, y los nacionales el de Lázaro Cárdenas y Zamora.

Como se puede apreciar, los dos aeropuertos internacionales del estado se localizan en dos de las ciudades-destino más importantes en la que se articula la ruta Don Vasco, aunque la mayoría del turismo interno (nacional) realiza su traslado por vía terrestre.

$\mathrm{Al}$ respecto, la procedencia geográfica de los turistas que visitan estas regiones se encuentran divididos en dos: nacionales e internacionales. El turismo nacional representa el $88 \%$ del total de visitantes al estado, mientras que el $12 \%$ proviene del extranjero. Los cuatro estados emisores de turistas hacia Michoacán son: Ciudad de México y Estado de México (22\%), Jalisco (12\%) y Guanajuato (8.1\%), esto se asocia con la 
proximidad de la entidad que les permite tener una mayor interacción, sin olvidar a otros como Querétaro (6.2\%), Puebla (4.4. \%), Nayarit (3.6\%) y Sinaloa (2.1\%). El turismo de orden internacional proviene, principalmente, de Estados Unidos, España, Canadá y Francia, seguido de países como Bélgica, Argentina y Perú (Figura 4).

Figura 4. Flujos turísticos nacionales e internacionales a Michoacán.

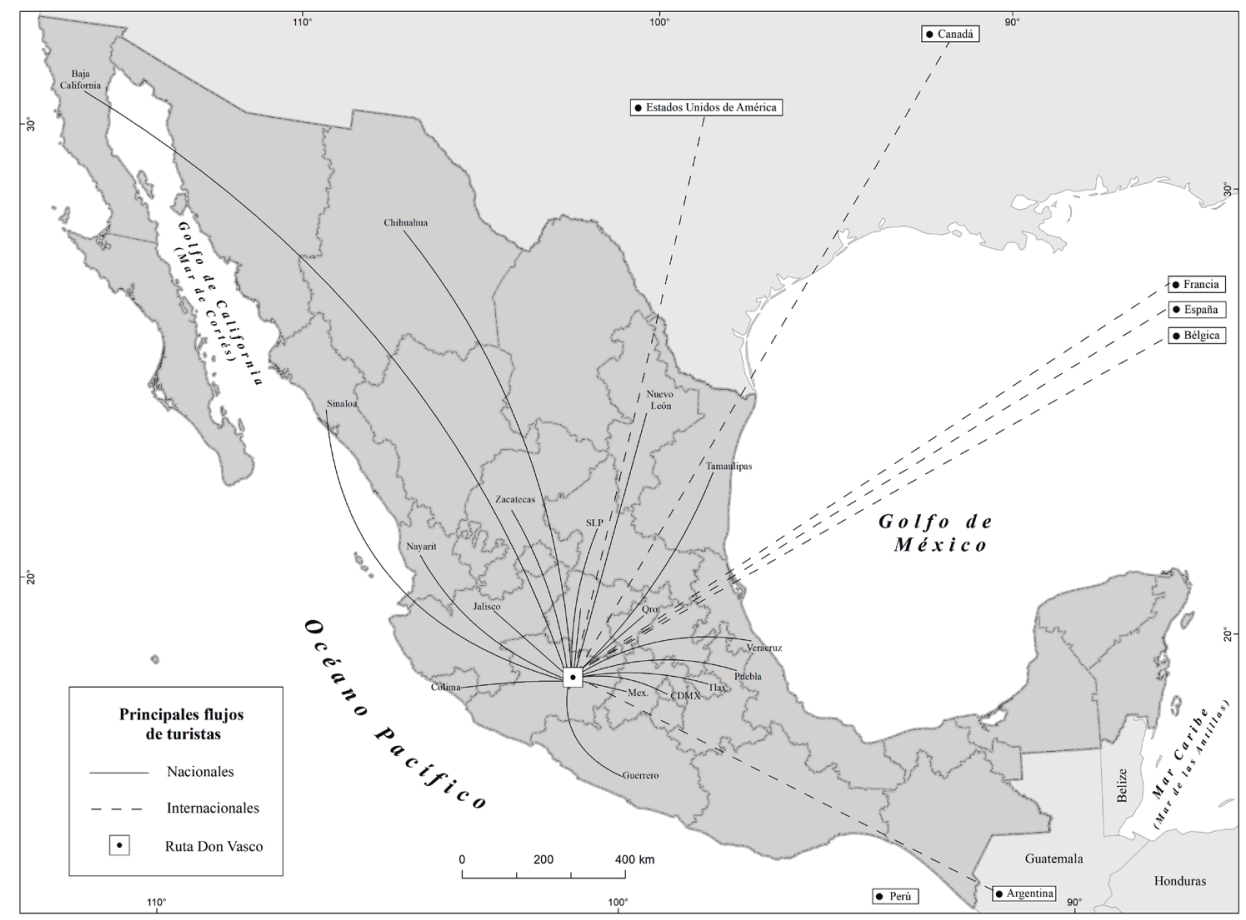

Fuente: Elaborado con base en el trabajo de campo, marzo-abril, 2018.

Finalmente, es importante señalar también algunas consideraciones que surgen respecto a la dinámica espacial de la ruta Don Vasco y el desarrollo socioeconómico que se busca promover para las dos regiones (Lacustre y Meseta Purhépecha) por las que ha sido trazada. Si bien el objetivo de integrar a varios pueblos y comunidades indígenas que antes no habían sido contempladas para el desarrollo turístico, sobretodo de la Meseta Purhépecha, con el fin, por un lado, de paliar sus condiciones de marginalidad y pobreza mientras que, por el otro, se busca ampliar el número de recursos 
patrimoniales para integrarlos a la oferta del turismo cultural del estado por medio de la ruta, la realidad es que la mayoría de estas poblaciones no cuenta con la infraestructura turística adecuada de hospedaje y prestación de servicios, aunado a que no poseen ningún tipo de conocimiento o capacitación en hostelería y de atención al visitante.

Al ser pueblos y comunidades que basan su sustento diario en la agricultura, de ser jornaleros agrícolas u obreros de la construcción, la producción artesanal y el envío de remesas por parte de los migrantes radicados en Estados Unidos, su principal insumo lo representa la manufactura de artesanías en calidad de souvenirs, su patrimonio cultural (material e inmaterial) expresado en la arquitectura vernácula, sus festividades tradicionales, música y danzas, comida y su identidad étnica. Elementos culturales que, si bien contribuyen a la creación de ese imaginario turístico y social sobre ese "Michoacán indígena", es conveniente mencionar que el turismo no representa interés alguno para la mayoría de los habitantes de estas poblaciones. Lo que ocurre es un proceso de cosificación de las comunidades y los actores sociales, al ser vistos como meros recursosatractivos. Esto último, se debe a que los principales impulsores de la ruta -gobierno del estado y los actores mencionados en líneas anteriores- no realizaron previamente un diagnóstico comunitario para evaluar el consenso e interés de los actores locales para ser incluidos en la ruta. Incluso, varios de los entrevistados durante el trabajo de campo dijeron desconocer sobre la existencia de ésta.

Aunque se plantea una articulación entre regiones a través de la ruta para la ampliación del espacio turístico y el fortalecimiento del turismo cultural como principal modalidad que consolide a Michoacán en este ámbito hasta ahora no ha sido posible su concreción, si se toma en cuenta lo enunciado en líneas anteriores. Salvo el caso de la ciudad de Uruapan y otras como Paracho, que representan casos aislados. Por ejemplo, el Centro de Interpretación de la Ruta Don Vasco facilita toda la información posible sobre festividades, arquitectura, danzas, artesanías y gastronomía que existe en todos los pueblos y comunidades de ambas regiones incluidas en la ruta, con el objetivo de que el turista planifique su itinerario al interior de esta y decida visitar los lugares que más le interesen. Sin embargo, comúnmente delimita su itinerario a visitar únicamente las ciudades de Uruapan, Pátzcuaro, la isla de Janitzio en el lago de Pátzcuaro, la zona arqueológica 
del municipio de Tzintzuntzan -situadas en la región Lacustre- y la ciudad de Morelia por su relativa cercanía, conectividad y fácil accesibilidad. En todo caso, suelen ser los turistas extranjeros que, motivados por realizar actividades de ecoturismo y geoturismo en la comunidad serrana de Angahuan, donde se ubica el volcán Paricutín, que en su paso por la ciudad de Uruapan deciden trasladarse a la Meseta Purhépecha, particularmente a esta comunidad y a la población de Paracho, cuya fama se debe a la construcción tradicional de guitarras de excelente calidad a nivel mundial.

Como refieren Hiriart y Minguez (2016), una de las grandes debilidades que se presentan en la operatividad de la ruta es la ausencia de un seguimiento o monitoreo de resultados para determinar la eficacia de los programas de turismo cultural, en términos de calidad de la infraestructura turística, de la derrama económica y mejor en la calidad de vida de las poblaciones residentes, del estado de conservación del patrimonio edificado, o de las regiones y localidades incluidas en esos programas. Además, de que se otorga un protagonismo excesivo al marketing turístico, en vez de ponderar una articulación y ordenamiento eficiente e integral del territorio como un sistema turístico (Hiriart y Minguez, 2016).

En consecuencia, a pesar de que la ruta Don Vasco ha sido diseñada y planeada por especialistas en materia de turismo y otras disciplinas afines, la inadecuada y carente infraestructura de comunicaciones y servicios turísticos en las comunidades incluidas en la ruta, sobre todo en aquellas que se encuentran localizadas en la Meseta Purhépecha, aunado a la falta de capacitación en materia de prestación de servicios turísticos, administración de recursos financieros y humanos y la violencia que impera en la zona, derivada de los conflictos intercomunitarios y el narcotráfico, hasta ahora no ha propiciado el desarrollo esperado para éstas. Lo que en términos de gestión turística del territorio y el patrimonio ha propiciado una disociación en materia de planificación turística, donde las políticas de planificación del territorio, desarrollo urbano y conservación del patrimonio edificado, sin toma en cuenta el patrimonio cultural inmaterial y natural, no se articulan en el mismo nivel, y quedan sesgadas bajo la rectoría de la secretaría de turismo estatal (Hririart y Minguez, 2106). 


\section{Conclusiones}

Tras identificar los elementos patrimoniales culturales y naturales (recursos turísticos) que conforman la oferta turística de Michoacán para promover el turismo cultural como la principal modalidad que le permita posicionarse en el mercado nacional e internacional en este ámbito, la creación de la ruta Don Vasco busca contribuir a ello, además de incidir en la ampliación del territorio en el que la actividad turística destaque como actividad económica que contribuya al desarrollo socioeconómico regional de las poblaciones indígenas más pauperizadas, pero que cuentan con una vasta riqueza patrimonial y natural (recursos). Sobre todo, de aquellas que se ubican en la región Meseta Purhépecha.

Como se pudo apreciar, la conformación del espacio turístico (turistificación) en Michoacán es un proceso de larga data, si se toman en cuenta las referencias históricas señaladas líneas arriba, destacando el caso de las ciudades de Pátzcuaro, Morelia y Uruapan, cuya ubicación geográfica les permite mantenerse hasta el día de hoy como los principales nodos turísticos de la entidad por contar con la mayor infraestructura turística y captar los principales flujos de visitantes, además de constituirse como el eje por el cual la ruta Don Vasco busca articular a las dos regiones de estudio.

A ocho años de haber sido creada, la ruta Don Vasco no ha logrado su consolidación a pesar de contar con las características enunciadas por Torres Bernier (2006): como destino, producto y recurso. Como bien señala este autor, a pesar de que el estudio del turismo cultural y el espacio turístico, como concepto, tienen una tradición consolidada a partir de numerosos análisis, las rutas turísticas apenas si están estudiadas desde una perspectiva teórica, quedándose casi siempre en los aspectos netamente culturales o descriptivos. De ahí la importancia en destacar su vínculo con el territorio en términos espaciales, como en el caso aquí abordado, con el objetivo de destacar la dimensión espacial, como dimensión constitutiva del turismo. Cuyo análisis implica considerar por el igual el papel de los diversos actores sociales que intervienen en este proceso, tomando en cuenta que el turismo es, ante todo, una práctica social con implicaciones territoriales específicas. 
Federico Gerardo Zúñiga-Bravo

Tourism space and cultural tourism through the Don Vasco route in Michoacán, Mexico

\section{Referencias}

Almirón, A. (2004). Turismo y espacio. Aportes para otra Geografía del turismo. En: GEOUSP-EspaÇo e Tempo, 16, 167-180.

Arcila, M., Fernández, A. y López, J.A. (2015). Rutas turístico-culturales e itinerarios culturales como productos turísticos: reflexiones sobre una metodología para su diseño y evaluación. Análisis espacial y representación geográfica: innovación y aplicación, Zaragoza: Universidad de Zaragoza-AGE. (pp.463-471).

Ávila, P. (2008). La cultura del agua en los pueblos indígenas de la Meseta Purhépecha. Agua y diversidad cultural en México. México: Instituto Mexicano de Tecnología del Agua-UNESCO. (pp. 39-53).

Boullón, R. (2006). Espacio turístico y desarrollo sustentable. En: Aportes $y$ transferencias, Vol. 10 (2), 17-24.

Bringas, N. y González, I. (2003). Algunos aspectos sobre el turismo en la frontera norte de México. Por las fronteras del norte. Una aproximación cultural a la frontera México-Estados Unidos. México: CONACULTA/FCE. (pp.272-301).

Callizo, J. (1991). Aproximación a la Geografía del Turismo, Madrid: Ed. Síntesis.

Chadefaud, M. (1987). Aux origins du tourisme dans les pays de l'Adour. Du mythe a l'espace: un essai de géographie historique. Département de géographie et d'aménagement de 1'Université de Pau et des Pays de L'Adour. Pau. Francia.

Chan, N. (2005). Circuitos turísticos. Programación y cotización, Buenos Aires. Argentina: Ediciones Turísticas.

Coll-Hurtado, A. (2016). Espacio y ocio: El turismo en México. Temas Selectos de Geografía de México. México: Instituto de Geografía-UNAM.

Flores, G., Nava, F. y Reynoso, C. (2016). Esto es música p'urhépecha... Pireris, pirekuas y turismo en Michoacán. Identidades en venta. Músicas tradicionales y turismo en México. México: IIS-UNAM, (pp. 31-67).

García, M. C. (2012). Los tarascos y los purhépechas. Dos formaciones históricas. México: INAH-Dirección de Estudios Históricos.

Gobierno del Estado de Michoacán-SECTUR (2010). Plan Estratégico 2010-2015. Ruta Don Vasco. Michoacán, México. 
Gobierno del Estado de Michoacán (2015). Plan de Desarrollo Integral del Estado de Michoacán 2015-2021. México, Michoacán.

Hiernaux, D. (1989). El espacio reticular del turismo en México. En: Geografia y Desarrollo. Red Nacional de Investigación Urbana. Volumen 2 (3), 31-39.

Hiernaux, D. (2015). Espacio turístico. Diccionario de Geografía Aplicada y Profesional. Terminología de Análisis y Gestión del Territorio. España: Universidad de León. (pp. 228-229).

Hiriart, C. y Mínguez, M.C. (2016). Coyunturas, retos, oportunidades y estrategias para el desarrollo de un producto turístico cultural en México: La Ruta Don Vasco en Michoacán. Completar con lugar y casa editora

Instituto Nacional para el Federalismo y el Desarrollo Municipal (s.f.). Enciclopedia de los municipios y delegaciones de México. Michoacán de Ocampo. Recuperado: http://siglo.inafed.gob.mx/enciclopedia/ EMM16michoacan/mediofisico.html

Instituto Nacional para el Federalismo y el Desarrollo Municipal (s.f.). Enciclopedia de los municipios y delegaciones de México. Michoacán de Ocampo. Recuperado: http://siglo.inafed.gob.mx/enciclopedia/ EMM16michoacan/regionalizacion.html

Instituto Nacional de Geografía y Estadística (2013). Conociendo Michoacán de Ocampo. México.

Instituto Nacional de Geografía y Estadística (2015). Encuesta intercensal. Principales resultados. Recuperado: http://internet.contenidos. inegi.org.mx/contenidos/productos/prod_serv/contenidos/espanol/ bvinegi/productos/nueva_estruc/promo/eic_2015_presentacion.pdf

Kemper, R. V. (1987). Urbanización y desarrollo en la región tarasca a partir de 1940. Antropología social de la región purhépecha. Zamora, Michoacán: El Colegio de Michoacán (pp. 67-96).

López, A. (2002). Análisis de los flujos turísticos en el corredor Los Cabos, Baja California Sur. En: Investigaciones Geográficas, Núm. 47,131-149.

Lozato, G. J. P. (1990). Geografia del Turismo. Barcelona: Ed. Masson. Machuca, A. (2008). Estrategias turísticas y segregación socio-territorial en regiones indígenas. Turismo, identidades y exclusión. México: UAM-Casa Juan Pablos. (pp. 51-96). 
Martínez, J. A. (2016). Bailar para el turismo. La Danza de los Viejitos de Jarácuaro como artesanía. Identidades en venta. Músicas tradicionales y turismo en México. México: IIS-UNAM. (pp. 139- 164).

Morére, M. N. (2012). Sobre los itinerarios culturales del ICOMOS y las rutas temáticas turístico-culturales. Una reflexión sobre su integración en el turismo. En: Revista de Análisis Turístico, 13, 57-68.

Nogués, P. A. (2017). Etnografía bajo un espacio turístico: sus procesos de configuración. Tenerife, España: PASOS. Revista de Turismo y Patrimonio Cultural. Colección PASOS, No. 13, pp.1-279.

Propin , F. E. y Sánchez, C. A. (2002). Estructura regional del turismo en México. En: Ería. Revista Cuatrimestral de Geografía, 59, 386-394.

Sánchez, C. A. y Propin, F. E. (2014). Volcanes y turismo: manifestaciones territoriales de las nuevas formas de la actividad turística. El caso del volcán Paricutín, México. Volcanes y ecoturismo en México y América Central. Heredia, Costa Rica: Editorial Universidad Nacional. (pp. 29-55).

s.a. (6 de enero, 2017). Creciente turismo en Michoacán. El Sol de Morelia. Michoacán, México. (p. 10). Recuperado: https://www.elsoldemorelia.com.mx/local/creciente-turismo-en-michoacan

s.a. (5 de febrero, 2018). México se consolida como potencia turística global. El Economista, Ciudad de México, México. (p. 15). Recuperado: https://www.eleconomista.com.mx/turismo/Mexico-se-consolida-como-potencia-Turistica-global--20180205-0027.html

Secretaría de Turismo-Gobierno Federal (2016). El turismo cultural en México representa una derrama económica por más de 184 mil millones de pesos del mercado nacional. En: Boletín de prensa. México.

Secretaría de Turismo-Gobierno Federal (2017). Turismo de naturaleza, un mercado global de 263 mil millones de dórales. En: Boletín de prensa. México.

Torres B., E. (2006). Rutas culturales. Recurso, destino y producto turístico. En: Boletín del Instituto Andaluz del Patrimonio Histórico, 60, 84-97. 